\title{
The RMP Analysis on the Protection of Textile Immaterial Cultural Heritage in
}

\author{
Beijing-Tianjin-Hebei \\ Liujun Guan ${ }^{1, a}$, Hong Zhao ${ }^{2, b}$, Yue Xiao ${ }^{3, c}$ \\ Tianjin Polytechnic University \\ ${ }^{1}$ No.399, binshui west road, xiqing district, tianjin, China \\ ${ }^{2}$ No.399, binshui west road, xiqing district, tianjin, China \\ ${ }^{3}$ No.399, binshui west road, xiqing district, tianjin, China \\ a 425119074@qq.com , b zhaohong300160@126.com, cxywdyx2@126.com
}

Keywords: Beijing-Tianjin-Hebei, Textile, Immaterial cultural heritage, RMP

\begin{abstract}
This paper was made to research on how to protect the traditional textile industry and its culture in RMP method: promoting the theory researches into textile cultural protections; making an practical investigation to textile industry and its protection and analyzing the conservative performance from aspects of resource, market and textile products under the influence of its cultural features and regional specialty, which will highly improve the effect of industrial production in the promotion of textile culture, and make an excellent integration between industrial resource and cultural protection .Moreover, textile industrial protections will help finding its cultural values and tastes in the observation of scientific exploitation and quality inspection .
\end{abstract}

\section{1 .Theory Base}

\subsection{RMP Theory}

RMP is also called Puang analysis theory. It was put forward by Professor Wubihu in 1999, who was then the doctoral supervisor in City and Environment College, Beijing University, and director of the research and planning center of tourism industry. [1] This theory is on the purpose of a systematic work flow chart for tourism product and service module, which was based on the evaluation of tourism products' market and resources and helped to make tourist-attraction-building plan centralized by one major tourism product. The flow chart of RMP theory analysis can be seen in Figure 1.

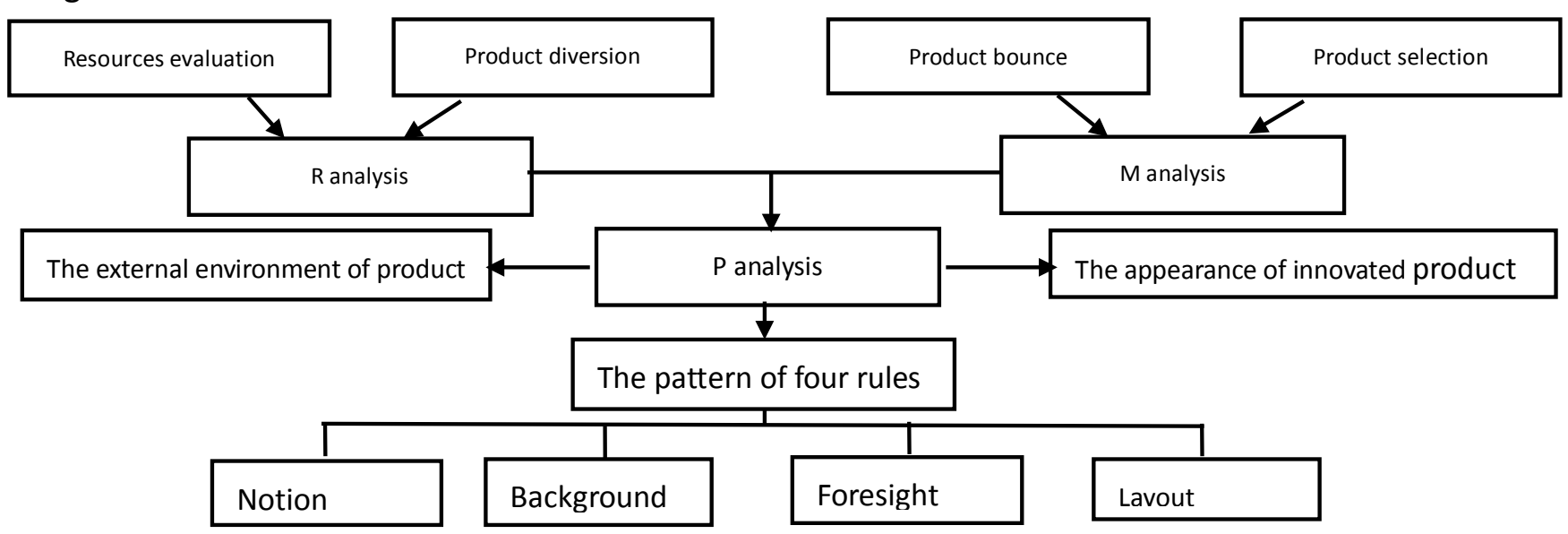

Fig.1. The control diagram of RMP theory analysis 
Given that the textile industry is developing very well and at the same time, its cultural protection activities were parted from products made for customers, so textile culture will not go too long. For the resource cultivation of textile products was booming under the lack of the conservative notion, consumers will not feel deep impressed in textile products and their culture. So, attaching importance on the RMP analysis of the resource and consumer market and making good combination between the local three areas can keep the interaction well among resources, products and market and help well understand the adaptation protection to the textile culture and products.

Chart 1 the representative textile items in the immaterial heritage protection project in Beijing-Tianjin-Hebei

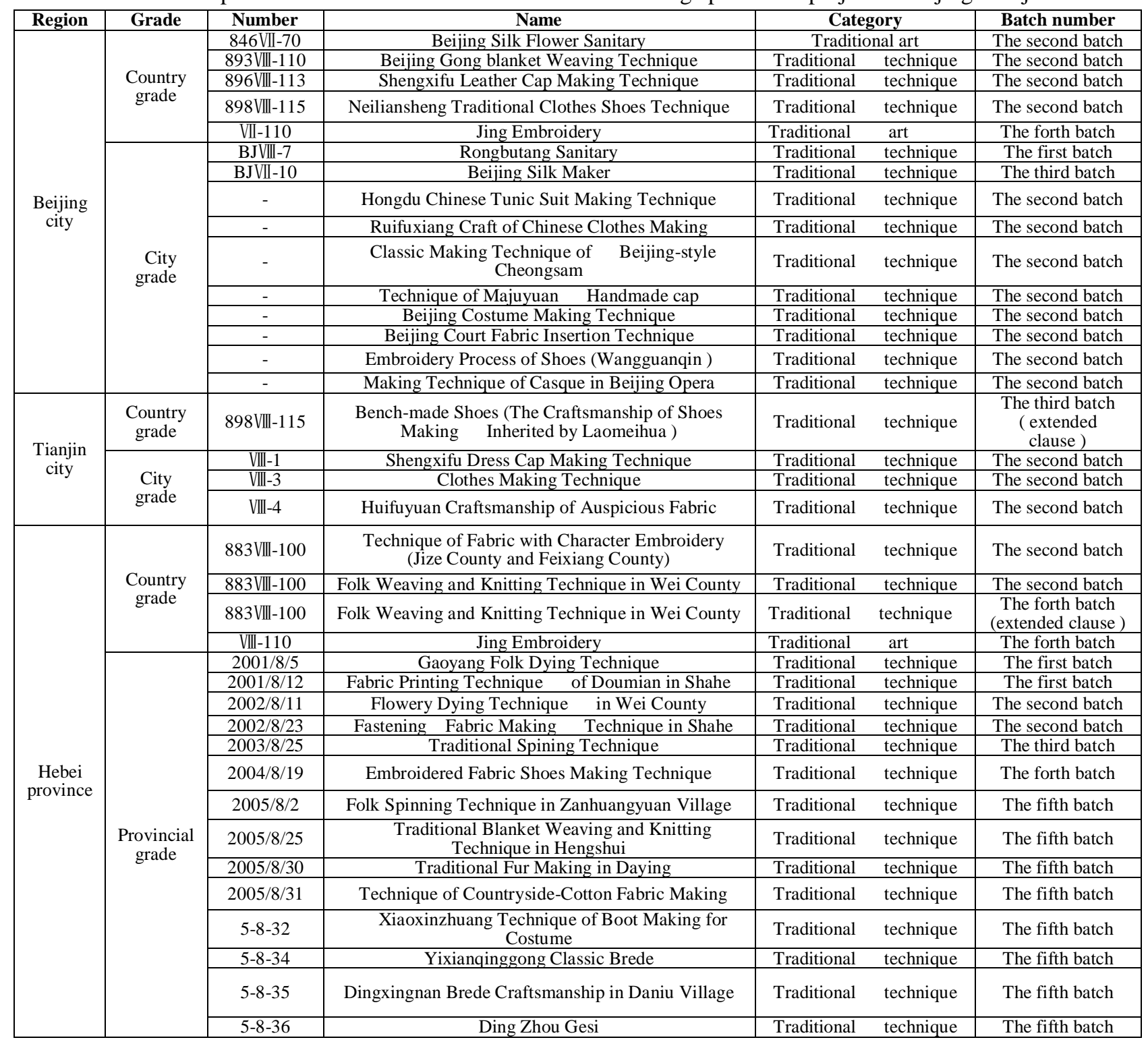

Source: the website of immaterial cultural heritages in Beijing-Tianjin-Hebei

\section{2 .The $R$ analysis on the Textile immaterial cultural heritage protection in Beijing-Tianjin-Hebei}

$\mathrm{R}$ (resource). Currently, there are 86 items of textile culture in four batches of national immaterial cultural heritage protection projects, published by Chinese cultural department. As we take a look into the heritage record of Beijing-Tianjin-Hebei, this can be seen in two categories traditional craftsmanship and traditional art. As can be seen in chart 1, this area has a large group of textile heritages, among which 8 items of them have gone through national immaterial heritage 
protection project, and 27 have gone through provincial or municipal protection project. With their resourceful historic contents, and a gathering of connotations, these items have become tourist attractions.

From the above description, we can be clear that there are some features in textile resources.

Firstly, textile cultural items were uneven in regional distribution. In Hebei, where there exist 11 municipals, most of the items were scattered in four cities, Handan, Xingtai, Hengshui and Baoding. Historically, these four cities were located at the back land of ancient Yan and Zhao countries, which have been the booming area in ancient China, with advanced handicrafts, flourished cultural and economic communications during its long history. However, most ancient poor areas, such as Zhangjiakou, Tangshan, Chengde, Cangzhou didn't have textile heritages historically because of poverty.

Secondly, In terms of grade and quantity, Beijing has 5 national and 10 municipal intangible cultural heritages in textile respectively, totaled 15 heritages; Hebei province has 2 national and 14 municipal intangible cultural heritages in textile respectively, totaled 16 heritages; Tianjin has 1 national and 3 municipal intangible cultural heritage in textile respectively, totaled 4 heritages. Tianjin is late in development, a city that obtains fast development in modern times, the foundation for development of handicraft industry is relatively weak compared with Beijing and Hebei province, therefore, the number of intangible cultural heritages in textile is few.

\section{The $M$ analysis of textile items in Beijing-Tianjin-Hebei}

$\mathrm{M}$ (market).In this section, we will make a deep analysis of the textile items' market protection in three views, market background, market competition and market cognition.

\subsection{Market background analysis}

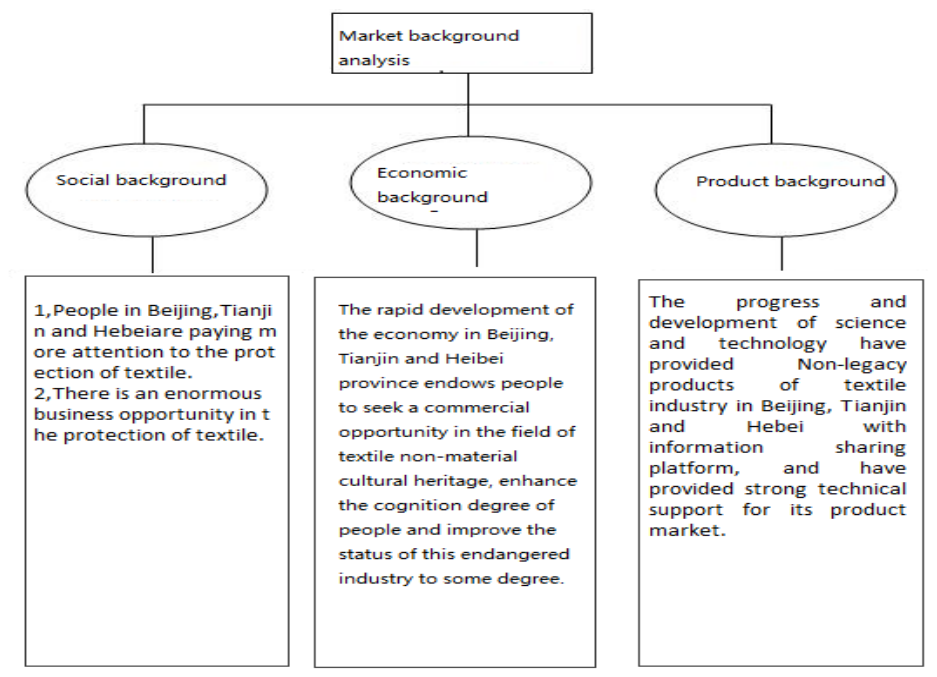

Fig.2. The market background analysis of textile items in Beijing-Tianjin-Hebei

\subsubsection{Social background analysis}

Some products in correlation to the textile project were very popular in market although they are very expensive, like Jingxiu, Laomeihua fabric shoes, and Shengxifu leather cap. These products are large in margin. Investing money into textile production is not just a matter of economy and margin, but also can propel the industrialization of textile culture and local development in Beijing-Tianjin-Hebei.[2]

\subsubsection{Economic background analysis}

In recent years, the fast economic development in Beijing-Tianjin-Hebei has greatly achieved 
the textile protection: people in high living quality and rich environment would give a lot of business opportunities to the textile industry. As a result, more and more people would get familiar with textile culture. One point we cannot overlook is that people are forgetting the protection of textile culture and a lot of textile sanitary have been lost and suspend in broadcasting.

\subsubsection{Product background analysis}

Currently, many local companies have managed to build the bridge between the textile investor and the craftsmanship holders, through which both of them can communicate through a certain network platform, and cooperation comes out. This kind of service is charged through successful cooperation, which produce a lot of business opportunities and at the same time can promote the development of textile culture. Besides, in the information age, the booming of e-commerce would give a strong support to marketing of traditional textile products.

\subsection{Market competition analysis}

The market competitiveness of traditional textile products seems to be obvious through market competition analysis: textile protection costs relatively low sum of money, consequently companies can invest more money into projects on the textile talent cultivation, textile cultural protection, market investigation and so on. We believe that in the high tide of immaterial heritage protection throughout the country, textile culture and its important items protection will get more and more support and encouragement in the future. However, some disadvantages cannot be neglected. Now, many companies are only to pursue the recent profit. As a result, in the near future, they will not go too long or grow well, and the behavior of making profit but ignoring protection is prevailed in the textile industry. Besides, textile market is still immature. So textile culture protection will going through a hard and long time because of a large number of textile items, big distribution areas and a complex work of official collection.

\subsection{Market cognition analysis}

To comprehensively investigate the cognition status of people in Beijing, Tianjin and Hebei province for the local textile intangible cultural heritage, this study has posted the questionnaire. The results showed that $44 \%$ people were not clear about the textile intangible cultural heritage in their hometown, not to mention the detailed list of the textile intangible cultural heritage. Apart from that, 45\% people did not hear about the textile intangible cultural heritage at all and did not understand its directories, which indicated that they had low cognition degree of the directories of the textile intangible cultural heritage. As for the Intangible Cultural Heritage Day, only 20\% of the 260 participants selected correct date, which represented that the Intangible Cultural Heritage Festival cannot present its essential contents to people since people only pay attention to the external form of the festival. Therefore, people only hear about the festival but cannot remember the date of the festival. As for the products of the textile intangible cultural heritage, the inherent value of the products only accounted $29 \%$ among the factors that could induce consumers to purchase the products. In view of the value cognition of the textile non-material cultural heritages, $13 \%$ of participants believed that the products of the textile intangible cultural heritage were no better than common textile products and only $21 \%$ of participants regarded them as the nationalized artworks. In conclusion, people in Beijing, Tianjin and Hebei lack a systematic cognition of the textile intangible cultural heritage, which always pay more attention to the extrinsic values, including the hand feeling, color, texture, pricing and environmental mark.

\section{The $P$ analysis of spinning product protection in Beijing-Tianjin-Hebei}

$\mathrm{P}$ (product).The bottle-neck problem of textile protection is the textile product protection; 
they archly appeared in three points. Firstly, hard working in the collection process costs too much human work, material resources and money. This is because it is large in number and type, and complex in style. Secondly, traditional protection methods are product acquisition, product record, adjustment. Documentation, conservation, approaches and so on. The publishing and advertisement to mass has been done with a lot of media like journal, book, and cinema corpus and so on. Thirdly, with the surge of cultural protection declaration throughout the country, some local authorities in the three areas realized the great advantages of the declaration. They intended to broaden the public stature, get government subsidy and absorb the foreign investment, and have not been based on the purpose of guarding for country heritage, which resulted in the flavor reversion of textile culture and destruction of folk custom. [4]

To be concluded, firstly in order to improve the development of textile protection in the three areas, we should make a blueprint on the development of textile resources, market, and products: in terms of resources, we should enforce the investigation of textile products in local areas and build a network platform for heritage holders. In terms of the market, we should increase people's cognition on the textile product, propel the informative communication of textile protection; in terms of the product adaptation, we should make punishment on any illegal acts about textile industry and achieve benefit maximization.

\section{Acknowledgement}

This paper was supported by the project of Tianjin philosophy and moral science Ethnic Immaterial Cultural Heritage Protective Adaptation Behavior Approach (keynote)(TJYY16 -004 ).

\section{References}

[1] Wang Jie, "The notion and method of immaterial cultural heritage protection J]", People Forum, 2015 (29):185-187.

[2] Hou Xiaoying, "The relationship approach among the three bodies: Enactment Policy, Constituent Establishment and its Holders [D]”, 2015 Yunnan Art College Art College in Kunming.

[3] Zhu Han, Zhao Rong, "The immaterial cultural heritage and its research based on the RMP--Jinan, Shandong for Instance [J]”, Northwest Academic Act (Philosophy and Moral Science Edition), 2013 (02):137-140.

[4] Anne,Chen Yan, Wu Lanping, Zhang Kaixi. "The resource integration of textile bodiless cultural heritage [J]”,Silk,2015 (10):56-62. 